\title{
trabalho
}

issn: 1808 - 799X

ano 9 - edição especial, número 13 - 2011

GRUPO DE PESQUISA TRABALHO E EDUCAÇÃO - GPTE ( UFMT)

\section{CONSIDERAÇÕES SOBRE O BINÔMIO TRABALHO E EDUCAÇÃO: UM OLHAR PANTANEIRO}

\author{
Edson Caetano \\ Email: Caetanoedson@hotmail.com
}

\section{RESUMO}

A racionalização econômica e do trabalho de cunho neoliberal, intensificou significativamente a dominação e exploração dos trabalhadores, aumentou as contratações precárias, informais e temporárias, sobrecarregou os trabalhadores que possuíam emprego formal, aumentou o contingente de trabalhadores desempregados e ampliou o tempo médio de procura por trabalho.

A conjugação dos elementos apontados anteriormente e a necessidade de garantir a reprodução ampliada da vida, fez com que um número crescente de trabalhadores (re)construíssem diferentes estratégias de organização do trabalho que, apesar de estarem inseridas na sociedade capitalista, evidenciam uma lógica que se contrapõe a mesma.

\footnotetext{
${ }^{1}$ Doutor e M estre em Educação pelo Programa de Pós-Graduação em Educação da Universidade Estadual de Campinas. Professor Adjunto do Departamento de Teoria e Fundamentos da Educação, Instituto de Educação, Universidade Federal de Mato Grosso, Programa de Pós-Graduação em Educação, Grupo de Pesquisa Trabalho e Educação.
} 
A teoria marxista e o materialismo histórico nos auxiliam na tentativa de compreensão da dimensão educativa do trabalho, pois a produção da vida material e social produz saberes sobre a relação do homem com a natureza, com o trabalho, com seus pares e com uma nova concepção de trabalho e de mundo. Portanto, este artigo tem o objetivo de discutir por um lado, a organização do processo de trabalho e por outro, a produção associada, vivenciada por trabalhadores que não sucumbiram à lógica do capital.

PALAVRAS-CHAVE: trabalho, trabalho como princípio educativo, produção associada.

\section{Introdução}

O Grupo de Pesquisa Trabalho e Educação é formado por pesquisadores da Graduação e do Programa de Pós-Graduação em Educação da Universidade Federal de Mato Grosso, mestrandos e alunos da graduação da Área de Ciências Humanas. O GPTE foi criado em 2010 e está inserido na Linha de Pesquisa: Movimentos Sociais, Política e Educação Popular do Programa de PósGraduação em Educação da Universidade Federal de Mato Grosso. Seu objeto de estudo é a relação Trabalho e Educação que se desenvolve através da linha de pesquisa: O MUNDO DO TRABALHO E A FORMAÇÃO HUMANA.

Os resultados dos estudos/ pesquisas realizados no âmbito do GPTE têm sido discutidos em eventos científicos locais, regionais e nacionais e publicados de forma a contribuir para a ampliação e o fortalecimento da pesquisa sobre Trabalho e Educação. Os estudos desenvolvidos pelos integrantes do Grupo tem possibilitado a elaboração de Dissertações de Mestrado, pesquisas de Iniciação Científica, artigos científicos, capítulos de livros e comunicações orais em eventos. Priorizamos o desenvolvimento de estudos e pesquisas sobre temáticas vinculadas aos fundamentos econômicos, culturais, políticos e sociais do trabalho e dos processos formativos humanos.

\section{O Campo de Pesquisa}


Os estudos/pesquisas desenvolvidos no GPTE situam-se em um campo específico que prioriza as reflexões sobre 0 trabalho enquanto categoria eminentemente humana, entendendo que o homem se humaniza através do trabalho e das relações sociais construídas a partir deste. Nesse sentido, o trabalho é tido como elemento central não só no que se refere ao desenvolvimento histórico do homem, mas na tentativa de compreensão/explicação do real.

Marx (1982) afirma que todos os seres vivos só sobrevivem porque tomam posse dos produtos da natureza em seu proveito. Contudo, isso não acontece da mesma forma, pois os vegetais e alguns animais irracionais fazem isso de forma direta e os restantes dos animais, como o homem, alteram o estado natural desse produto para satisfazer as suas necessidades.

Pode-se distinguir os homens dos animais pela consciência, pela religião ou pelo que se queira. Mas eles mesmos começam a se distinguir dos animais tão logo começam a produzir seus meios de vida, passo que é condicionado por sua organização corporal. Ao produzir seus meios de vida, os homens produzem, indiretamente sua própria vida material.(...) $O$ que eles são coincide, pois, com sua produção, tanto como o que produzem como também com o modo como produzem. O que os indivíduos são, portanto, depende das condições materiais de sua produção (MARX \& ENGELS, 2007, p. 87).

Pode-se dizer que através da transformação da natureza o trabalho se concretiza e que esta é uma atividade intrínseca do homem, ou seja, o homem é trabalho - o homem humanizou-se através do trabalho. $O$ trabalho é o agente fundante do ser social.

Além disso, Braverman (1981, p. 51-52) ressalta que

no trabalho humano o mecanismo regulador é o poder do pensamento conceptal (grifo do autor), que tem origem em todo um excepcional sistema nervoso central [...] sejam quais forem as capacidades possíveis de estimularem animais mediante as engenhosas formas de tutelagem humana, não se mostrou possível estimular-lhes a capacidade de manipular representação simbólica, sobretudo em suas formas superiores como a linguagem articulada. Sem símbolos ou linguagem o pensamento conceptual deve permanecer rudimentar e, ademais, não pode ser livremente transmitido através de grupo ou às gerações seguintes.

Entendemos, pois, o trabalho como sendo uma atividade na qual participam o homem e a natureza e que através da sua ação corporal, o primeiro impulsiona, regula e controla a natureza para apropriar-se de seus recursos. Com isso, ele atua sobre a natureza e a modifica, mas ao fazer isso, acaba modificando a sua própria natureza, isto é, o homem já não é o mesmo de antes da ação, ele transformou-se em algo que não existia anteriormente. 
Do mesmo modo, pode-se dizer que o trabalho do homem deu origem à cultura humana já que, através da linguagem e da memória, transmitiram aos seus pares e as gerações posteriores a criação de instrumentos de trabalho, comportamentos, modos de vida, relações de produção, entre outros. Portanto, o trabalho humano foi social e culturalmente desenvolvido.

Os meios de trabalho $e$ as forças de trabalho humanas foram se desenvolvendo e modificando as relações sociais e de produção. Sobre isso, observa Marx (1982) que os modos e as formas que bens materiais foram produzidos em cada sociedade determinaram o seu regime social.

As análises efetivadas no interior do grupo partem da categoria trabalho, ancorada no arcabouço teórico formulado por Marx, porém concebendo o trabalho não apenas no seu sentido ontológico, mas, sobretudo como princípio educativo. Isso equivale dizer que saberes/conhecimentos são construídos no e pelo trabalho. No interior das relações sociais, ao trabalhar, os homens produzem conhecimento; o que os permite manter, conservar, criar e recriar múltiplas formas de existência.

Se a existência humana não é garantida pela natureza, não é uma dádiva natural, mas tem de ser produzida pelos próprios homens, sendo, pois, um produto do trabalho, isso significa que o homem não nasce homem. Ele forma-se homem. Ele não nasce sabendo produzir-se como homem. Ele necessita aprender a ser homem, precisa aprender a produzir sua própria existência. Portanto, a produção do homem é, ao mesmo tempo, a formação do homem, isto é, um processo educativo. A origem da educação coincide, então, com a origem do homem mesmo. (SAVIANI, 2007, 154).

A partir da centralidade do trabalho e do seu princípio educativo, surge no interior do GPTE uma dupla preocupação: de um lado a tentativa de compreensão dos sentidos do trabalho como condição natural do homem e a sua possibilidade educativa e de outro lado, a preocupação reflexiva sobre a configuração assumida pelo trabalho no modo de produção capitalista, visto que, segundo Marx, no referido modo de produção

o trabalhador torna-se tanto mais pobre quanto mais riqueza ele produz, quanto mais a sua produção aumenta em poder e extensão. O trabalhador torna-se uma mercadoria, tanto mais barata, quanto maior número de bens produz. Com a valorização do mundo das coisas aumenta em proporção direta a desvalorização do mundo dos homens. $O$ trabalho não produz apenas mercadorias; produz-se também a si mesmo e ao trabalhador como uma mercadoria, e justamente na mesma proporção com que produz bens (2004, p. 59).

As concepções teóricas que dão sustentação às pesquisas realizadas pelos componentes do grupo situam-se no campo do marxismo: Karl Marx, 
Friedrich Engels, Antonio Gramsci, Vladimir Lênin, Harry Braverman, E. P. Thompson, David Harvey, Eric Hobsbawm e outros.

\section{Pesquisas em Desenvolvimento}

A partir da década de 80 do século passado, consolida-se mundialmente 0 modelo neoliberal de acumulação do capital, através do regime de acumulação flexível, que segundo Harvey (2003) preconizava uma nova organização da produção - uso intensivo da tecnologia e da microeletrônica, aumento da produtividade, controle de qualidade, trabalho em células, Just-in-time -; a busca de novos serviços, produtos e mercados; a criação de novas necessidades e a flexibilidade do consumo, da produção e do trabalho. Este modelo está assentado na desestruturação do mercado de trabalho - desemprego, precarização do trabalho e na exclusão crescente de contingentes de trabalhadores-, no enfraquecimento dos sindicatos, na diminuição dos rendimentos e na crise da sociedade salarial - com a diminuição do proletariado industrial e do número de postos de trabalho com carteira de trabalho- (Castel,1998).

Frente a uma conjuntura extremamente desfavorável, onde o trabalhador transita entre o desemprego e o subemprego, este se forçado a criar múltiplas estratégias de trabalho e de sobrevivência. A economia popular solidária é uma das estratégias que os sujeitos pertencentes aos setores populares lançam mão, visando a garantia da reprodução ampliada da vida através de práticas econômico-sociais que se diferenciam da racionalidade da economia capitalista.

Neste cenário, a educação passou a ser concebida enquanto uma mera mercadoria com uma finalidade instrumental bem definida: "o problema do desemprego só será resolvido com a ampliação dos investimentos em educação" (TIRIBA, 2004, p.97). Os relatórios do Banco Mundial (1995), assim como outros organismos internacionais reguladores, sustentam a argumentação da existência de uma vinculação direta entre educação e trabalho, indicando que a educação possibilita o aumento da produtividade/competitividade das empresas e contribui à adaptação dos trabalhadores às mudanças técnicas promovidas pelo capital no âmbito da produção. 
O raciocínio economicista que norteia o posicionamento neoliberal fundamenta-se na teoria do capital humano (SCHULTZ, 1962 e HARBISON, 1965) e transfere para o indivíduo a responsabilidade acerca do seu sucesso no trabalho, alcançado através da estabilidade no emprego e mobilidade e social, por um lado, e o fracasso vivenciado pelo desemprego, por outro.

$\mathrm{Em}$ tal realidade multiplicam-se os projetos de formação/educação destinados aos trabalhadores, procurando desenvolver no trabalhador determinadas habilidades requeridas pelo capital e ao mesmo tempo, estimular o empreendorismo, visando à flexibilização das relações entre capital e trabalho, sobre este ultimo aspecto, citamos como exemplo o 'falso cooperativismo' (que se caracteriza pelo trabalho precarizado, sem carteira assinada e sem as garantias da Legislação Trabalhista).

No sentido de se questionar as premissas da economia capitalista, por um lado, e, por outro, a pedagogia da fábrica (KUENZER, 1986), nos propusemos a analisar os vínculos entre trabalho, educação e economia, buscando,

ademais, expressar uma dada unidade da diversidade, perseguindo-se a exposição de possíveis caminhos político-educativos da(s) pedagogia(s) da produção associada, tanto no plano teórico-metodológico como no plano da ação prática, (PICANÇO e TIRIBA, 2004, p. 28).

Para se pensar em uma educação popular para os trabalhadores pertencentes aos setores populares, há que se articular a economia popular e a educação popular, ou seja, utilizar os saberes dos trabalhadores e da comunidade como matéria-prima para o ensino no intuito de se construir um conhecimento que possibilite a afirmação destes enquanto sujeitos.

Nesse intento, devemos buscar na ação prática os fundamentos do processo educativo, pois, em momentos de crises, as pessoas aprendem mais com a vida do que nas escolas e também, a produção de saberes e tradições são revividas e realimentadas no fazer do trabalhador. Além disso, é preciso identificar como os saberes dos trabalhadores (experiências) podem contribuir para a construção de novas práticas econômico-sociais. Tiriba (2004, p.82) afirma que "estimular a produção associada é fortalecer outros mercados que se contraponham à lógica do mercado capitalista" e esse também é um dos desafios da pedagogia da produção associada. 
Pensar em uma pedagogia da produção associada equivale presumir uma pedagogia dos trabalhadores que

parte do principio de que na luta pela sobrevivência, convivem nas redes associativas diferentes concepções e práticas de solidariedade (...), a pedagogia da produção associada é tecida tendo como um de seus fios a diversidade de práticas solidárias dos setores populares" (TIRIBA, 2004, p.93),

e buscam a reprodução ampliada da vida e não a reprodução do capital.

O crescente desemprego, a precarização do trabalho e a exclusão social, resultantes da reestruturação produtiva implementada pela política neoliberal, a partir de 1980, atingiram parcela considerável da classe trabalhadora. Nesse período, uma parcela crescente da classe trabalhadora, preocupada em garantir a reprodução ampliada da vida e em alguma medida resistir aos ditames da sociedade capitalista moderna, (re)criaram múltiplas estratégias de trabalho e de sobrevivência e com isso, multiplicaram-se as experiências no âmbito da economia (popular) solidária.

De maneira oposta a égide do sistema capitalista, onde o trabalhador aliena a sua força de trabalho em troca do salário, na economia (popular) solidária, a mercadoria não se separa das mãos do produtor e inexiste a propriedade individual dos meios de produção.

Apesar de estarem inseridas no sistema capitalista, essas estratégias apresentam pressupostos que questionam o ideário neoliberal: autogestão, administração/organização participativa e democrática do trabalho, cooperação, autonomia, distribuição igualitária dos frutos do trabalho e das perdas monetárias ou divididas segundo decisão coletiva, liberdade individual, reciprocidade e comensalidade; diferenciando-se e constituindo-se em uma nova organização do processo de trabalho.

Todas essas características da produção associada fazem com que o trabalho não seja subordinado ao capital, não seja alienado e nem alienante, não gere a mais-valia e possibilita que os envolvidos construam coletivamente uma nova concepção de mundo e de trabalho.

Tiriba (2006, p. 80) manifesta que essa estratégia é a "possibilidade de os trabalhadores resgatarem o sentido do trabalho, recuperar a energia que o capital Ihes sugou, direcionando-a no sentido de uma organização da produção inspirada na hegemonia do trabalho sobre o capital". 
Por serem todos donos dos meios de produção e a repartição dos frutos do trabalho ser igualitária, o princípio da igualdade reforça os laços de pertencimento, solidariedade e compartilhamento no interior do grupo. Aqui não há exclusão social, exploração no trabalho e tão pouco, a competitividade. Além disso, a solidariedade e a cooperação são importantes por manterem redes de produção e venda das mercadorias produzidas, onde todos os trabalhadores são participantes; bem como redes que extrapolam o âmbito da produção e do trabalho, isto é, que incidem na produção social da vida em coletividade.

Contudo, o comportamento desses trabalhadores/trabalhadoras provém da nova cultura do trabalho e da experiência com a lógica capitalista que muitos viveram, pois como ressalta TIRIBA (2009), é fundamental que transformem suas vivências pregressas e atuais em experiências propriamente formadoras.

Em suma, a economia (popular) solidária é uma estratégia de organizar o trabalho e a vida que pode contribuir para a formulação de uma crítica classista aos ditames do capital, bem como, a conquista da liberdade como sujeitos históricos.

Conceber a educação e os saberes numa perspectiva ampliada, ou seja, que não se restrinja ao espaço da escola, não implica desconsiderar a importância da reflexão acerca da educação formal, não se trata de estabelecer critérios valorativos entre a educação formal e a educação não formal. Trata-se isto sim, do reconhecimento da existência de espaços diversos aonde os saberes podem ser construídos e dentre esses múltiplos espaços destacamos o da produção ou do trabalho que se constitui no lócus preferencial das pesquisas realizadas atualmente pelo GPTE.

Mas o homem não é apenas ser natural, mas ser natural humano, isto é, ser existente para si mesmo, por isso, ser genérico, que, enquanto tal, tem de atuar e confirma-se tanto em seu ser quanto em seu saber. Consequentemente, nem os objetos humanos são os objetos naturais assim como estes se oferecem imediatamente, nem o sentido humano, tal como é imediata e objetivamente, é sensibilidade humana, objetividade humana. A natureza não está, nem objetiva nem subjetivamente, imediatamente disponível ao ser humano de modo adequado (MARX, 2004, p. 128).

\section{Os (Des)Caminhos Teóricos-Metodológicos}

O objetivo geral da pesquisas realizadas no âmbito do GPTE é analisar as 
relações entre trabalho e educação presentes nos processos de produzir a vida associativamente, em especial nas chamadas "comunidades tradicionais" da baixada Cuiabana (Mato Grosso). Nesse sentido, os saberes da experiência, apreendidos nas práticas concretas do trabalho associado personificam a reflexão sobre o trabalho enquanto princípio educativo.

Os objetivos específicos que norteiam as pesquisas desenvolvidas no grupo são: a) identificar o significado do trabalho associado (a partir da visão que os trabalhadores e trabalhadoras envolvidos expressam), procurando situá-lo e distingui-lo da lógica que orienta o processo de trabalho na sociedade capitalista; b) refletir sobre os fundamentos e a identificação dos elementos constitutivos da(s) pedagogia(s) da produção associada, enquanto concretização de um processo educativo que se contrapõe à concepção utilitarista da educação que é expressa pela visão neoliberal; c) analisar, alguns aspectos que estão presentes na reprodução ampliada da vida e na reprodução da vida social de trabalhadores e trabalhadoras que participam da produção associada. Os aspectos a serem analisados são os seguintes: questões de gênero, relações de poder, divisão do trabalho, processos de decisão, distribuição das riquezas, relações com a comunidade local e com os movimentos populares, preocupação com a questão ambiental, objetivos do associativismo e concepção de mundo.

A reflexão possibilitada pelos objetivos específicos precedentes deve ampliar a compreensão que temos acerca da cultura do trabalho, forjada em grande medida, nas práticas econômico-sociais, através da economia popular solidária e dos saberes da experiência.

Elegemos o materialismo histórico enquanto pressuposto no intuito de compreendermos as questões que envolvem a produção material e imaterial a partir do trabalho associado realizado por homens e mulheres. Acreditamos que não exista método alheio a uma dada concepção de realidade, pois,

o método de análise, na perspectiva dialética materialista, não se constitui na ferramenta asséptica, uma espécie de "metrologia" dos fenômenos sociais, que nas perspectivas que aqui denomino de metafísicas é tomada como garantia da "cientificidade, da objetividade e da neutralidade". Na perspectiva materialista histórica, o método está vinculado a uma concepção de realidade, de mundo e de vida no seu conjunto (FRIGOTTO, 1989, p. $76-77$ ).

Nesse sentido, no processo dialético do conhecimento da realidade o que se persegue é a crítica e o pensamento crítico do entendimento do mundo, ou 
seja, o conhecimento que se dá na e pela práxis, em uma perspectiva que vislumbre uma ação transformadora da realidade.

Atualmente estão sendo desenvolvidas cinco pesquisas pelas mestrandas do GPTE e que se inserem em nosso projeto de Pesquisa: $A(s)$ pedagogia(s) da produção associada: educação, cultura do trabalho e economia popular nas comunidades da baixada cuiabana. Apresentamos abaixo um resumo de cada uma das referidas pesquisas:

a) Trabalho e construção de saberes na comunidade do Imbé. A pesquisa tem como ponto de partida a reflexão sobre a produção dos saberes do/no trabalho na comunidade tradicional do Imbé-MT, saberes que potencializem relações sociais e econômicas diferentes das impostas pelo sistema capitalista hegemônico. Vivemos um cenário de precarização estrutural do trabalho que tem acentuado seus traços destrutivos cada vez mais, marcado pelo crescente desemprego e exclusão social; em que trabalhadores (as) pertencentes às camadas populares buscam na economia popular solidária a garantia da reprodução ampliada da vida. Desta forma, buscamos compreender o processo da produção associada na comunidade tradicional do Imbé, enquanto uma estratégia de produção que questiona a lógica capitalista, apesar de estar inserida na mesma. Pois, apesar de haver um sistema político-econômico instituído, existem práticas e experiências em que indivíduos se auto-organizam de uma maneira diferenciada dos valores capitalistas impostos, e são esses indivíduos que me nos propomos estudar. Para tanto formulamos os seguintes questionamentos: quem são esses trabalhadores(as)? Como se organizam? Como produzem? Que relação tem com o passado histórico? Dentre outros aspectos. Utilizamos o método de análise do materialismo histórico, para tentar compreender o nosso objeto de estudo, tendo o entendimento que não existe método alheio a uma concepção da realidade. Para o desenvolvimento da análise partimos da categoria "Trabalho", baseado no arcabouço teórico de Marx, para refletir e analisar a realidade e concebemos o trabalho não apenas enquanto sendo uma categoria ontológica, mas também enquanto "princípio educativo" com base em Gramsci. Os homens ao realizarem o seu trabalho não só aprendem a produzir mercadorias, mas ao produzi-las, esses homens e mulheres da comunidade tradicional do Imbé também produzem saberes, educação, conhecimento e relações sociais. Nesse sentido objetivamos 
refletir sobre esses "saberes da experiência" baseado nos pressupostos formulados por Thompson, bem como dos estudos de Tiriba, pois compreendemos que é através do trabalho que os indivíduos da comunidade executam e constroem os saberes, e que embora estejam inseridos dentro de uma sociedade capitalista, se utilizam de conjecturas diferentes, como os de solidariedade, auto-gestão, ou seja, vivem a vida a partir de uma perspectiva diversa da lógica capitalista, e este contexto é que nos propomos a estudar. Pensamos que a educação não se efetive somente na escola, mas que ocorra em outros espaços, como por exemplo, no âmbito do trabalho. Procuramos compreender de que forma os chamados saberes da experiência concreta, ou seja, o lidar com a reprodução ampliada da vida, que saberes são esses explicitados e construídos por homens e mulheres. Desse modo, o objetivo da pesquisa situa-se na compreensão sobre a construção e utilização de estratégias de produção da vida material e imaterial, na comunidade do Imbé, através da produção associada, mais especificamente como estes trabalhadores e trabalhadoras produzem saberes através do trabalho;

b) Saberes, cultura do trabalho e produção associada: entre bananas e utopias. A pesquisa está sendo realizada na Comunidade Capão Verde - Mato Grosso. Partindo do pressuposto marxista onde o trabalho é princípio educativo e que, portanto, saberes são construídos no e sobre o trabalho, o objetivo da pesquisa é identificar e ressignificar saberes provenientes da produção livre e associada. Para isso, utilizamos o materialismo histórico - dialético como método de análise no intuito de apreendermos o objeto em sua experiência concreta e a metodologia do Estudo de Caso. Entrevistamos 12 trabalhadores e trabalhadoras de Capão Verde e registramos os dados obtidos em áudios, vídeos, fotografias e diário de bordo. Paralelamente à pesquisa de campo, realizamos leituras de autores clássicos como Marx, Gramsci, Thompson, Saviani, Frigotto, entre outros. A nossa intenção era subsidiar nossa análise a respeito das seguintes indagações: O que é trabalho? Quais as especificidades do trabalho no modo de produção capitalista? Como se efetiva a relação entre trabalho e educação? Qual o significado do trabalho enquanto princípio educativo? O que é a produção livre e associada? Como e para que se educam os trabalhadores? Marx afirma que ao realizar o trabalho, o homem transforma a natureza e se autotransforma, pois 
durante a produção ele projeta em sua mente o que vai produzir e com isso, acaba criando um objeto para determinado sujeito. Nesse objeto (mercadoria) está impressa, intrinsecamente, sua concepção de mundo e de homem, o que demonstra estreita relação entre trabalho manual e intelectual. O capitalismo industrial ao tornar o trabalho uma atividade fragmentada e cujo objetivo é aumentar a mais-valia, trouxe consigo a concepção da educação dual: intelectualizada para a classe dominante e profissionalizante para a classe trabalhadora. Mesmo no modo de produção capitalista, existem modos de organizar o processo de trabalho (produção associada) que se pautam na solidariedade, autogestão, coletividade, liberdade, autonomia, igualdade e democracia. Tal realidade pode ser observada em Capão Verde - eles não só produzem derivados de banana a partir dos princípios descritos acima, como a própria vida social. Todos são donos dos meios de produção e dos frutos do trabalho, evidenciando que vislumbram somente a garantia da reprodução ampliada da vida. A produção da existência pautada nesses princípios promove modos de pensar a vida e o mundo, hábitos, costumes, saberes e comportamentos que sobrevivem desde a fundação da Comunidade e que diferem da ideologia neoliberal. Dentre eles, podemos citar o muxirum, a casa de amparo, a organização do processo de trabalho, as festas de santo, os remédios caseiros; cuja reprodução durante o cotidiano desses trabalhadores não interfere na produção material. Em outras palavras, eles não deixam de realizar essas atividades em função do trabalho; a magnitude cultural prevalece sobre o ganho material. Assim, esperamos dar visibilidade a experiência e aos saberes desses trabalhadores e trabalhadoras, tendo a utopia de inspirarmos possíveis ações formativas/educativas orientadas para a formação de um trabalhador de um novo tipo;

c) Na modelagem do barro a modelagem da vida: os fios educativos e solidários na produção coletiva das mulheres. Desde o final da década de 1980, para subsistir e/ou se contrapor a lógica capitalista, os trabalhadores excluídos do mercado de trabalho, por meio de ações coletivas autogestionárias ocupam fábricas falidas, ativam sua produção, criam associações cooperativas de produção, consumo e crédito. A economia popular solidária surge como opção para os trabalhadores articularem a produção pelo trabalho solidário. Assim, o 
trabalho associado se institui no contexto da formação social capitalista e tem conquistado o seu lugar enquanto uma alternativa para a classe trabalhadora tanto da cidade quanto do campo, libertar-se das diversas formas do trabalho alienado. Os sujeitos sociais estão vivendo um processo de disputa por legitimação e validação social desse modo de produção da existência, vinculada à reprodução ampliada da vida, e não do capital, e tem como objetivo a valorização do trabalho e dos seres humanos. Este resumo refere-se à pesquisa de mestrado em andamento na Universidade Federal de Mato Grosso - Cuiabá, com o título provisório: "Das mãos das mulheres artesãs as relações educativas construídas no processo de autogestão do trabalho". O locus é um Distrito de Progresso, distante $15 \mathrm{~km}$ da cidade de Tangará da Serra (220 km da capital Cuiabá), situada a sudoeste do estado de Mato Grosso. A associação "Arte da Terra" é constituída por seis mulheres artesãs com idades entre 36 e 65 anos, que há dois anos na perspectiva da autogestão e do trabalho solidário, se dedicam à confecção de peças ornamentais como fontes de água, tuiuiús (ave típica do pantanal), tangará (ave que deu nome a cidade), pratos de parede, jarros, potes, todos feios de barro. Nosso objetivo tem sido compreender quais os fios que tecem educação/trabalho neste ambiente das associações e como se estabelecem as relações, do trabalho, como atividade humana, suas dimensões ontológicas e históricas, quais os agentes pedagógicos e os espaços aprendentes que na experiência de tirar da argila a arte, possibilitam a construção de uma nova cultura do trabalho de uma 'nova' economia. A pesquisa qualitativa segue na perspectiva do materialismo histórico e do estudo de caso, e os instrumentos foram as observações, os relatos orais, e as entrevistas. Estamos neste momento na fase de análise dos dados, e redação dos capítulos da dissertação, mas já é possível dizer que as mulheres continuam a produzir, apesar da renda mensal não ser suficiente para suprir suas necessidades materiais. Ainda em reflexões iniciais, vemos na experiência das mulheres artesãs a possibilidade de superação do modo de produção capitalista, aonde as trabalhadoras vão aprendendo a se organizar, a reivindicar seus direitos; a compreender as relações sociais e a função que nelas desempenham, é, portanto, educativo. As mulheres não apenas acreditam na possibilidade da transformação, mas assumem a luta e a construção de um novo mundo. E se apropriam do processo de trabalho em sua 
totalidade, contribuindo assim para um mundo mais justo e menos excludente, é o entendimento de que a realidade não é, está sendo e por esse motivo passível de ser transformada;

d) As mulheres da associação comunitária e de micro produtores rurais de joselândia: um estudo sobre trabalho e produção de saberes. O presente trabalho visa apresentar o objeto de pesquisa que resultará na Dissertação de Mestrado em Educação, realizado na Universidade Federal de Mato Grosso - UFMT. O projeto está vinculado ao Grupo de Pesquisas em Trabalho e Educação e busca estabelecer algumas reflexões quanto às mulheres da Associação Comunitária e de Micro Produtores Rurais de Joselândia. Tomando como referência contribuições teóricas formuladas por autores do campo marxista, buscaremos com este projeto de pesquisa, investigar as experiências de e no trabalho que marcam as trajetórias de vida das mulheres da Associação Comunitária e de Micro Produtores Rurais de Joselândia e as implicações que a reestruturação produtiva trouxe a esta comunidade. Além disso, analisaremos a produção de saberes que acontece dentro desta associação, que surge a partir do desejo de algumas mulheres da comunidade de garantirem a reprodução ampliada da vida através do trabalho. A organização do processo de trabalho pretendida por estas trabalhadoras situa-se no âmbito da economia popular solidária, em que pretendem produzir mercadorias a partir do trabalho associado. Para isso, iniciaremos dando uma visão geral acerca do objeto de pesquisa e logo depois levantaremos algumas questões teóricas relacionadas ao nosso tema TrabalhoEducação, explícitas no trabalho. Por fim, serão abordados os processos teóricos metodológicos a serem utilizados no decorrer da pesquisa;

e) o trabalho associado e a produção de sua cultura correspondente: elementos em debate em campina de pedra. Historicamente contextualizado no interior das contradições que marcam o modo de produção capitalista, notadamente em um período predominante de reestruturação na produção sob o crivo ideológico neoliberal, onde a classe trabalhadora não tem o domínio sobre seu trabalho, assim como o acesso aos seus direitos básicos enquanto cidadãos, este trabalho busca trazer a conhecimento, maneiras de se conduzir a vida e o trabalho fora dos ditames alienantes a que se propõe esta dinâmica de acumulação flexível, evidenciando práticas de trabalho e de saberes que se opõem à lógica da 
exploração capitalista.Tomando como aporte teórico o materialismo histórico, estudaremos de quais maneiras se dá a produção material e imaterial da vida na comunidade Campina de Pedra - MT, local onde o trabalho é produzido associadamente, a partir do cultivo de cana-de-açúcar e produção de açúcar mascavo, melado e rapudura em um engenho coletivo, onde os trabalhadores e trabalhadoras produzem e reproduzem suas vivências e saberes no âmago de novas e diferenciadas maneiras de produção social da vida. Buscaremos investigar as formas pelas quais o trabalho e o conhecimento acerca deste e da própria reprodução da vida, não apresentam limites definidos, o se que constitui como uma cultura própria dos indivíduos que ali compartilham coletivamente suas vidas. Nessa perspectiva questionamos acerca dos saberes que podem contribuir para a constituição de uma nova cultura do trabalho e para a consolidação de relações econômico-sociais que se coloquem enquanto maneiras diferenciadas da lógica capitalista. Igualmente pretendemos questionar de que maneira os trabalhadores e trabalhadoras envolvidos nos processos produtivos vão acumulando saberes no decorrer da vida, com a intenção de construir a partir de desses saberes acumulados, uma "pedagogia da produção associada". Para tanto buscamos apreender a articulação existente na comunidade Campina de Pedra entre a práxis produtiva e a práxis educativa, o que nos direciona a problematizar elementos como, por exemplo, o trabalho enquanto princípio educativo, a economia popular solidária e a educação popular.

\section{Considerações Finais}

Embora a sociedade atual se regule pelo capitalismo, ainda existem pequenas comunidades ou grupo de pessoas que procuram se organizar de forma coletiva, igualitária e sem exploração do trabalho alheio, apenas para manter a reprodução ampliada da vida.

Diante do que foram expostos, os saberes provenientes da produção associada da vida e dos bens materiais reforçam o sentimento de pertencimento ao grupo e a vontade de manter uma cultura ligada à questão da terra, o que possibilita que eles lutem coletivamente contra possíveis problemas sociais, econômicos, territoriais e culturais. 
Sobre isso, TIRIBA (2008, p. 48), descreve que a educação pode acontecer em outros espaços e não somente nas escolas, ou seja, é uma cultura proveniente do trabalho, ou seja, "são códigos, padrões, normas, conhecimentos, saberes, crenças, valores e criações materiais (instrumentos, métodos, técnicas), (...) que regulam as ações e comportamentos humanos".

Tendo o trabalho como princípio educativo, eles educam a si mesmos e aos outros em uma relação dialética, o que contribui para valorização dos trabalhadores e da formação humana; já possibilita, uma outra visão de mundo, de homem e de prática social.

No nosso entendimento, este tipo de estudo possibilitará, aos trabalhadores e trabalhadoras da economia popular solidária e aos professores e educadores preocupados com a educação popular, uma forma de repensar a formação humana e a práxis produtiva. E, isto, se tornará possível através da consideração das nuances e detalhes que conformam o cotidiano de homens e mulheres que resistem e persistem em viver a vida associativamente. Esse viver coletivo poderá indicar novos meios de se ensinar e aprender um ofício, bem como, estratégias que assegurem a reprodução ampliada da vida frente às constantes crises no mundo do trabalho.

\section{Referências Bibliográficas}

BRAVERMAN, Harry. Trabalho e capital monopolista. A degradação do trabalho no século XX. Rio de Janeiro, Zahar,1981.

CASTEL, Robert. As metamorfoses da questão social. Uma crônica do salário. São Paulo, Vozes, 1998.

FRIGOTTO, Gaudêncio. O Enfoque da Dialética Materialista Histórica na Pesquisa Educacional. In: FAZENDA, Ivani (org.). Metodologia da pesquisa educacional. São Paulo, Cortez, 1989.

GRAMSCI, Antonio. Cadernos do Cárcere. Vol. 1. Introdução ao estudo da filosofia. Rio de Janeiro, Civilização Brasileira, 2006.

. Cadernos do Cárcere. Vol. 2. Os intelectuais. O principio educativo. Jornalismo. Rio de Janeiro, Civilização Brasileira, 2006. 
HARBISON, Frederick Harris. Recursos humanos para o desenvolvimento. Rio de Janeiro, Fundação Getúlio Vargas (USAID), 1965.

HARVEY, David. Condição pós-moderna: uma pesquisa sobre as origens da mudança cultural. São Paulo, Loyola, 2003.

KUENZER, Acácia Zeneida. Pedagogia da fábrica. São Paulo, Cortez, 1986.

LÊNIN, Vladimir. Sobre a juventude. Santos, Editorial Estampa, 1979.

MARX, Karl. O Capital. Livro 1, volume I, São Paulo, Difel, 1982.

. Manuscritos Econômicos Filosóficos. São Paulo, Boitempo, 2004.

MARX, Karl; ENGELS, Friedrich. A ideologia alemã. São Paulo, Boitempo, 2007.

Saviani, Dermeval. Trabalho e educação: fundamentos ontológicos e históricos.

Revista Brasileira de Educação, v. 12, n. 34, jan./abr. 2007, 152 - 165.

SCHULTS, Theodore Willian. O valor econômico da educação. Rio de Janeiro, Zahar, 1962.

THOMPSON, Edward Palmer. A Formação da classe operária inglesa. Volume 1. A árvore da liberdade. Rio de Janeiro, Paz e Terra, 1987.

. Os românticos. A Inglaterra na era revolucionária.

Rio de Janeiro, Civilização Brasileira, 2002.

. Costumes em comum. Estudos sobre a cultura

popular tradicional. São Paulo, Companhia da Letras, 2008.

TIRIBA, Lia. Pedagogia da produção associada. In: TIRIBA, Lia; PICANÇO, Iracy.

Trabalho e educação: arquitetos, abelhas e outros tecelões da economia popular solidária. São Paulo: Santuário, 2004.

. Cultura do trabalho, produção associada e produção de saberes.

Publicado em Educação Unisinos, Vol.10, № 2, maio-agosto 2006, p. 116-122. In: http://www.unisinos.br.

,Cultura do trabalho, autogestão e formação de trabalhadores associados na produção: questões de pesquisa. Artigo publicado em Perspectiva - Revista do Centro de Ciências da Educação/UFSC, n. 27, vol.26, n.1, jan/jun. Florianópolis. 2008.

. Cultura do trabalho. In: Trabalho, educação e economia (popular) solidária: elementos para uma pedagogia da produção associada. Relatório Final de Pesquisa. Niterói: Universidade Federal Fluminense, p. 48-51, 2009. 
